\title{
Drug-Induced Hyperglycemia as a Potential Contributor to Translational Failure of Uncompetitive NMDA Receptor Antagonists
}

\author{
Eric Yuhsiang Wang, ${ }^{1,2}$ and Ted Weita Lai ${ }^{1,2,3,4}$
}

https://doi.org/10.1523/ENEURO.0346-21.2021

${ }^{1}$ Graduate Institute of Biomedical Sciences, China Medical University, Taichung 404, Taiwan, ${ }^{2}$ School of Medicine, China Medical University, Taichung 404, Taiwan, ${ }^{3}$ Drug Development Center, China Medical University, Taichung 404, Taiwan, and ${ }^{4}$ Translational Medicine Research Center, China Medical University Hospital, Taichung 404, Taiwan

\begin{abstract}
Hyperglycemia is a comorbidity in $60-80 \%$ of stroke patients; nevertheless, neuroprotective drugs like NMDA receptor (NMDAR) antagonists are typically assessed in normoglycemic animals at the preclinical stage before they are approved to enter clinical trials. Interestingly, as a possible explanation for the translational failure of NMDAR antagonists, it was recently reported that stroke occurring during nighttime causes smaller infarctions in rodents and therefore has a smaller window for neuroprotection. To investigate why stroke occurring during different circadian phases confers a difference in severity, we reanalyzed the published source data and found that some mice that were used in the daytime have higher blood glucose than mice that were used in the nighttime. We then repeated the experiments but found no difference in blood glucose concentration or infarct volume regardless of the circadian phase during which stroke occurs. On the other hand, induction of hyperglycemia by glucose injection reproducibly increased stroke severity. Moreover, although hyperglycemia increases infarction volume, which presumably would provide a larger window for neuroprotection, uncompetitive NMDAR antagonists were unexpectedly found to exacerbate stroke outcome by worsening hyperglycemia. Taken together, our new data and reanalysis of the published source data suggested that blood glucose during stroke, rather than the circadian phase during which stroke occurs, affects the size of the ischemic infarction; moreover, we have revealed drug-induced hyperglycemia as a potential reason for the translational failure of uncompetitive NMDAR antagonists. Future trials for this class of neuroprotective drugs should monitor patients' blood glucose at enrollment and exclude hyperglycemic patients.
\end{abstract}

Key words: circadian; excitotoxicity; hyperglycemia; neuroprotection; NMDA receptor; stroke

\section{Significance Statement}

Hyperglycemia is highly prevalent among stroke patients (60-80\%; Scott et al., 1999), and blood glucose is a chief determinant of stroke severity in the clinic. Nevertheless, preclinical stroke studies were typically performed using normoglycemic animals. Here, we reported evidence that uncompetitive NMDA receptor (NMDAR) antagonists, a major class of neuroprotective drugs, can exacerbate stroke outcome in hyperglycemic and diabetic mice. Our study revealed a previously unknown explanation for the translational failure of NMDAR antagonists, thereby providing new guidance for the future design of clinical stroke trials. In addition, this report serves as a case for the need to assess neuroprotective drugs in hyperglycemic animals before they should be approved to treat stroke patients in clinical trials.

Received August 21, 2021; accepted November 26, 2021; First published December 3, 2021.

The authors declare no competing financial interests.
Author contributions: E.Y.W. and T.W.L. designed research; E.Y.W. performed research; E.Y.W. and T.W.L. analyzed data; T.W.L. wrote the paper. 


\section{Introduction}

Despite the success of NMDA receptor (NMDAR) antagonism in some animal stroke models, NMDAR antagonists and NA1, a therapeutic peptide designed to minimize NMDAR-mediated free radical damage, have failed to demonstrate unequivocal clinical benefit in human stroke trials (Lai et al., 2014; Hill et al., 2020). Of the potential explanations for why inhibition of NMDARs or their release of free radicals has failed to translate from bench to clinic, several studies have explored the possibility that these therapeutic agents are neuroprotective only when certain experimental or clinical conditions are met. For example, two recent studies have supported the notion that these neuroprotective agents, including NMDAR antagonists and NA1, are effective only in animals subjected to middle cerebral arterial occlusion (MCAO), which produces a large hemispheric infarct, but not in animals subjected to distal MCAO (dMCAO), which produces a smaller localized cortical infarct (Liu et al., 2020, 2021). These findings complement previous reports showing that neuroprotection by MK801, a prototypical NMDAR antagonist, strongly depends on the type of cerebral ischemia that is used to assess drug efficacy (Buchan et al., 1991; LeBlanc et al., 1991; Nellgård et al., 1991; Nellgård and Wieloch, 1992). Moreover, even in the same stroke model, the neuroprotective efficacy of MK801 has been widely reported to be contingent on the body temperature of the animal during the experiment (Ikonomidou et al., 1989; Buchan and Pulsinelli, 1990; Corbett et al., 1990; Warner et al., 1991; Memezawa et al., 1995; Alkan et al., 2001; Gerriets et al., 2003).

Recently, one prominent study has added to the flurry of experimental evidence showing that neuroprotection by MK801 or $\alpha$-phenyl-butyl-tert-nitrone, a scavenger that can prevent NMDAR-dependent free radical release, is contingent on the conditions under which stroke occurs (Esposito et al., 2020). In particular, the authors report that these therapeutic agents are neuroprotective only in rats and mice when stroke is induced during the daytime (rodent sleep cycle) but not when stroke is induced during the nighttime (rodent wake cycle). Given that rats and mice are nocturnal animals, the authors suggested that the opposite phenomenon would be true in human stroke patients. Because human subjects enrolled in clinical trials mostly experience stroke during the daytime (human

This work was supported by research grants from the China Medical University (CMU109-MF-28), Ministry of Science and Technology (MOST1092320-B-039-010), National Health Research Institutes (NHRI-EX110-10803NI), and Drug Development Center, China Medical University, from the Featured Areas Research Center Program within the framework of the Higher Education Sprout Project by the Ministry of Education in Taiwan. E.Y.W. was supported by an undergraduate student research award from the Ministry of Science and Technology (MOST110-2813-C-039-027-B).

Acknowledgements: We thank Raymond Mengjing Lin for technical assistance.

Correspondence should be addressed to Ted Weita Lai at ted.weita@ me.com.

https://doi.org/10.1523/ENEURO.0346-21.2021

Copyright (C) 2021 Wang and Lai

This is an open-access article distributed under the terms of the Creative Commons Attribution 4.0 International license, which permits unrestricted use, distribution and reproduction in any medium provided that the original work is properly attributed. wake cycle), the findings of that study could have important implications for how stroke trials should be redesigned to properly assess the potential clinical benefits of these treatments. Furthermore, to explain why these neuroprotective agents are effective only during the daytime, the authors compared cortical infarction between animals in which stroke was induced during the daytime and those in which stroke was induced during the nighttime and found that cortical infarction, spread of the penumbra, and density of neurodegeneration were much more severe when stroke was induced during the daytime than when it was induced during the nighttime. Based on these findings, the authors suggested that there might be more room for neuroprotection when stroke occurs during the daytime (Esposito et al., 2020).

In light of a lack of in vivo data to explain the larger cerebral infarction in the daytime group in that study (Esposito et al., 2020), we reanalyzed the published source data on animal physiology from that study to check whether animals that underwent surgery in the daytime had higher blood glucose concentrations. As decades of clinical and experimental evidence have already established blood glucose to be a key factor in determining stroke severity in human patients and laboratory animals, we next asked whether exacerbating ischemic brain infarction by increasing blood glucose would unmask a neuroprotective effect of NMDAR antagonists in a stroke model that is otherwise resistant to protection by these drugs. Unexpectedly, we found that the opposite is true. Surprisingly, uncompetitive antagonists of NMDARs can further increase blood glucose in hyperglycemic animals, thereby exacerbating their stroke outcome.

\section{Materials and Methods}

\section{Mice and cerebral ischemia}

Adult male mice (C57BL/6; 7-10 weeks old; 21-30 g) were purchased from the National Laboratory Animal Center (Taipei, Taiwan), housed in our institutional animal care facility under a 12/12 h light/dark cycle and given free access to food and water. All study protocols were conducted in accordance with the Institutional Guidelines of the China Medical University for the Care and Use of Experimental Animals (IGCMU-CUEA) and were approved by the Institutional Animal Care and Use Committee of the China Medical University (IACUC-CMU; Taichung, Taiwan; Protocol no. CMUIACUC-2021-278). Cerebral ischemia was induced in these mice by transient $\mathrm{dMCAO}$ under brief isoflurane anesthesia as described previously (Liu et al., 2017). Each mouse was subjected to a 2-h occlusion period, during which the mouse was kept normothermic by means of an autoregulated heating pad with continuous feedback from a rectal temperature probe. After surgery, the mice were allowed to recover in their home cage, where they remained until killing by urethane overdose and perfusion with saline 24 $\mathrm{h}$ postischemia for collection of their brains for assessment of the infarction volume.

\section{Induction of acute hyperglycemia}

To produce a hyperglycemic state in the mice during stroke, mice received an injection of saline (vehicle 
control, i.p.) or $30 \%$ glucose in saline $(2.2 \mathrm{~g} / \mathrm{kg}$, i.p.) $20 \mathrm{~min}$ before the induction of cerebral ischemia by dMCAO; this injection typically resulted in a blood glucose concentration between 200 and $400 \mathrm{mg} / \mathrm{dl}$ before stroke onset. At the times specified in the manuscript, blood was collected from the severed tail, and blood glucose concentration was measured by a standardized glucometer (FORA, TD4272A).

\section{Induction of type 1 diabetes mellitus}

To induce diabetes mellitus in mice before stroke, mice received repeated injections of freshly prepared streptozotocin (STZ; $40 \mathrm{mg} / \mathrm{kg} / \mathrm{d}$, i.p.), dissolved in citrate buffer (50 mm, pH 4.5), for five consecutive days. This protocol induced diabetes mellitus, as confirmed by hyperglycemia (blood glucose $>200 \mathrm{mg} / \mathrm{dl}$ ) determined $8 \mathrm{~d}$ after the final dose of STZ, in 18 out of 22 mice. Those 18 diabetic mice were subjected to dMCAO $9 \mathrm{~d}$ after the final dose of STZ, and the four mice without diabetes were excluded without further experimentation.

\section{Quantification of brain infarction}

Isolated mouse brains were coronally sectioned at a thickness of $1 \mathrm{~mm}$ on a brain matrix, and each coronal section was bathed in $2 \%$ 2,3,5-triphenyltetrazolium (TTC; Sigma-Aldrich) at $37^{\circ} \mathrm{C}$ for $10 \mathrm{~min}$. The infarct and non-infarct areas of each coronal section were measured using the image analysis software ImageJ (NIH). Infarct volume was determined by multiplying the ipsilateral infarct area by the thickness of each coronal section. To account for potential edema in ischemic infarct, we also calculated a "normalized infarct volume corrected for edema" determined by multiplying normalized infarct area, calculated by subtracting ipsilateral non-infarct area from contralateral non-infarct area, by the thickness of each coronal section.

\section{NMDAR antagonists}

MK801 (Abcam, catalog \#ab120027), ketamine (SigmaAldrich, catalog \#K2753-1G), D-2-amino-5-phosphonovaleric acid (AP5; Cayman, catalog \#14539), and 3-(2-carboxypiperazin-4-yl)propyl-1-phosphonic acid (CPP; Sigma-Aldrich, catalog \#C104-5MG) were used in this study. For mice subjected to cerebral ischemia, drugs were administered 60 min before ischemia onset.

\section{Randomization and exclusion}

The investigators performing the surgery and quantification of brain infarction were blinded to the drug treatments until the completion of data analysis. As described above, four mice were excluded before surgery because STZ failed to induce diabetes mellitus (blood glucose $>200 \mathrm{mg} / \mathrm{dl}$ ) in those mice. In addition, the stroke surgery had a failure rate of $10.6 \%$ : 13 out of 123 mice were excluded because the mice died during surgery or soon after reperfusion while investigators were still blinded to the drug treatments (Table 4). The excluded mice were evenly distributed across experimental groups, and accounted for the differences in sample sizes between blood glucose concentrations data and infarction volumes data. As shown in Table 4, except for the four mice excluded because of failure to induce diabetes, the excluded mice had blood glucose concentrations similar to non-excluded mice. No data collected were excluded from analysis.

\section{Data presentation and analysis}

The data are presented as individual data points, with the error bars showing the mean \pm SEM. Differences between two groups were compared by unpaired $t$ test, and differences between multiple groups were compared by one-way or two-way ANOVA followed by Tukey's multiple comparisons test. Changes in glucose concentrations were compared by two-way repeated-measures ANOVA matching blood glucose from the same animal, which was followed by Tukey's multiple comparisons test.

\section{Results}

\section{Effect of blood glucose and circadian time of stroke on infarction volume}

The source data and data table published in the circadian study showed no difference between daytime and nighttime in terms of blood $\mathrm{pH}$, blood $\mathrm{pCO}_{2}$, blood $\mathrm{pO}_{2}$, blood pressure, and body temperature $(p>0.05$, Tukey's multiple comparisons test; Table 1; Esposito et al., 2020), all of which are potential factors that can contribute to a difference in stroke severity. Moreover, the source data and data table presented the blood glucose concentrations of the mice used in that study, including their blood glucose concentrations at $30 \mathrm{~min}, 60 \mathrm{~min}, 70 \mathrm{~min}$, and 24 $\mathrm{h}$ after cerebral ischemia, which was induced either during the daytime or nighttime and was with or without neuroprotective treatments (Esposito et al., 2020). Although the original report stated that blood glucose concentrations were similar across groups (Esposito et al., 2020), we found that the mice in the daytime [zeitgeber time (ZT)3ZT9; sleep cycle for mice] groups tended to have higher blood glucose concentrations than the mice in the nighttime (ZT15-ZT21; awake cycle for mice) groups (Fig. 1A$D$; Table 1). However, the difference was only statistically significant in drug-treated mice at $30 \mathrm{~min}(p=0.0155$, Tukey's multiple comparisons test) and 70 min postischemia ( $p<0.0001$, Tukey's multiple comparisons test), but not for either vehicle ( $p=0.5424$, Tukey's multiple comparisons test) or drug-treated mice ( $p=0.2161$, Tukey's multiple comparisons test) at $60 \mathrm{~min}$ postischemia (Fig. 1A-C; Table 1). For 60 min postischemia, we attempted to increase statistical power by pooling the blood glucose concentration data obtained in the daytime group and nighttime group, regardless of treatment received, and found that mice in the daytime group pooled together had higher blood glucose concentrations (334 $\pm 13 \mathrm{mg} / \mathrm{dl}$; $n=9)$ than mice in the nighttime group pooled together (blood glucose of $278 \pm 19 \mathrm{mg} / \mathrm{dl} ; n=8 ; p=0.0223$, $t$ test; Fig. 1D; Table 1). We did not analyze the $24 \mathrm{~h}$ blood glucose data because the source data for that was incomplete. Taken together, these analyses showed that 
Table 1: Statistical analysis of source data reported by Esposito et al. (2020)

\begin{tabular}{|c|c|c|c|c|c|c|c|c|c|c|}
\hline \multicolumn{11}{|c|}{30 min postischemia } \\
\hline & & \multicolumn{3}{|c|}{ Blood pH } & \multicolumn{3}{|c|}{$\mathrm{pCO}_{2}$} & \multicolumn{3}{|c|}{$\mathrm{pO}_{2}$} \\
\hline & & $N$ & Mean \pm SEM & $p$ value & $N$ & Mean \pm SEM & $p$ value & $N$ & Mean \pm SEM & $p$ value \\
\hline \multirow[t]{2}{*}{ Vehicle } & ZT3-ZT9 & 4 & $7.34 \pm 0.01$ & $0.6008^{2}$ & 4 & $39 \pm 2$ & 0.3587 & 4 & $193 \pm 22$ & $\overline{0.9176}$ \\
\hline & ZT15-ZT21 & 4 & $7.27 \pm 0.04$ & & 4 & $47 \pm 5$ & & 4 & $178 \pm 12$ & \\
\hline \multirow[t]{4}{*}{$\mathrm{PBN}^{1}$} & ZT3-ZT9 & 4 & $7.29 \pm 0.07$ & 0.1949 & 4 & $41 \pm 4$ & 0.6195 & 4 & $155 \pm 12$ & 0.5174 \\
\hline & ZT15-ZT21 & 6 & $7.39 \pm 0.003$ & & 6 & $35 \pm 1$ & & 6 & $186 \pm 15$ & \\
\hline & & & Blood gluco & & & Blood pres & & & Body tempera & \\
\hline & & $N$ & Mean \pm SEM & $p$ value & $N$ & Mean \pm SEM & $p$ value & $N$ & Mean \pm SEM & $p$ value \\
\hline \multirow[t]{2}{*}{ Vehicle } & ZT3-ZT9 & 4 & $217 \pm 16$ & 0.5101 & 4 & $92 \pm 5$ & 0.9059 & 4 & $37.1 \pm 0.2$ & 0.9880 \\
\hline & ZT15-ZT21 & 4 & $162 \pm 42$ & & 3 & $88 \pm 4$ & & 4 & $37.1 \pm 0.2$ & \\
\hline \multirow[t]{2}{*}{ PBN } & ZT3-ZT9 & 4 & $290 \pm 36$ & 0.0155 & 3 & $88 \pm 4$ & 0.9895 & 4 & $37.4 \pm 0.04$ & 0.9789 \\
\hline & ZT15-ZT21 & 6 & $165 \pm 9$ & & 6 & $87 \pm 3$ & & 6 & $37.3 \pm 0.1$ & \\
\hline \multicolumn{11}{|c|}{60 min postischemia } \\
\hline & & \multicolumn{3}{|c|}{ Blood pH } & \multicolumn{3}{|c|}{$\mathrm{pCO}_{2}$} & \multicolumn{3}{|c|}{$\mathrm{pO}_{2}$} \\
\hline & & $N$ & Mean \pm SEM & $p$ value & $N$ & Mean \pm SEM & $p$ value & $N$ & Mean \pm SEM & $p$ value \\
\hline \multirow[t]{2}{*}{ Vehicle } & ZT3-ZT9 & 5 & $7.35 \pm 0.02$ & 0.1124 & 5 & $36 \pm 2$ & 0.8346 & 5 & $170 \pm 6$ & 0.9944 \\
\hline & ZT15-ZT21 & 4 & $7.40 \pm 0.01$ & & 4 & $33 \pm 2$ & & 4 & $167 \pm 8$ & \\
\hline \multirow[t]{4}{*}{ MK801 } & ZT3-ZT9 & 4 & $7.29 \pm 0.02$ & 0.3365 & 4 & $40 \pm 2$ & 0.9996 & 4 & $171 \pm 8$ & 0.4415 \\
\hline & ZT15-ZT21 & 4 & $7.33 \pm 0.004$ & & 4 & $40 \pm 1$ & & 4 & $154 \pm 9$ & \\
\hline & & \multicolumn{3}{|c|}{ Blood glucose } & \multicolumn{3}{|c|}{ Blood glucose (pooled) } & \multicolumn{3}{|c|}{ Blood pressure } \\
\hline & & $N$ & Mean \pm SEM & $p$ value & $N$ & Mean \pm SEM & $p$ value & $N$ & Mean \pm SEM & $p$ value \\
\hline \multirow[t]{2}{*}{ Vehicle } & ZT3-ZT9 & 5 & $327 \pm 19$ & 0.5424 & \multicolumn{2}{|c|}{ ZT3-ZT9 all mice } & $0.0223 t$ test & 5 & $85 \pm 2$ & 0.9997 \\
\hline & ZT15-ZT21 & 4 & $283 \pm 27$ & & 9 & $334 \pm 13$ & & 4 & $85 \pm 2$ & \\
\hline \multirow[t]{2}{*}{ MK801 } & ZT3-ZT9 & 4 & $344 \pm 18$ & 0.2161 & \multicolumn{2}{|c|}{ ZT15-ZT21 all mice } & & 4 & $84 \pm 0.3$ & 0.9823 \\
\hline & $\mathrm{ZT} 15-\mathrm{ZT} 21$ & 4 & $273 \pm 30$ & & 8 & $278 \pm 19$ & & 4 & $85 \pm 2$ & \\
\hline \multicolumn{11}{|c|}{70 min postischemia } \\
\hline & & \multicolumn{3}{|c|}{ Blood pH } & \multicolumn{3}{|c|}{$\mathrm{pCO}_{2}$} & & $\mathrm{pO}_{2}$ & \\
\hline & & $N$ & Mean \pm SEM & $p$ value & $N$ & Mean \pm SEM & $p$ value & $N$ & Mean \pm SEM & $p$ value \\
\hline Vehicle & ZT3-ZT9 & 5 & $7.31 \pm 0.01$ & 0.9952 & 5 & $43 \pm 1$ & 0.9943 & 5 & $200 \pm 23$ & 0.6341 \\
\hline & ZT15-ZT21 & 4 & $7.32 \pm 0.03$ & & 4 & $44 \pm 4$ & & 4 & $165 \pm 27$ & \\
\hline PBN & ZT3-ZT9 & 4 & $7.18 \pm 0.08$ & 0.1682 & 4 & $45 \pm 5$ & 0.4566 & 4 & $155 \pm 16$ & 0.7998 \\
\hline & ZT15-ZT21 & 4 & $7.32 \pm 0.01$ & & 4 & $38 \pm 1$ & & 4 & $184 \pm 15$ & \\
\hline & & & Blood gluco & & & Blood pres & & & Body tempera & \\
\hline & & $N$ & Mean \pm SEM & $p$ value & $N$ & Mean \pm SEM & $p$ value & $N$ & Mean \pm SEM & $p$ value \\
\hline Vehicle & ZT3-ZT9 & 5 & $227 \pm 21$ & 0.8574 & 5 & $87 \pm 3$ & 0.9859 & 5 & $37.3 \pm 0.1$ & 0.8177 \\
\hline & ZT15-ZT21 & 4 & $200 \pm 7$ & & 3 & $86 \pm 2$ & & 4 & $37.5 \pm 0.1$ & \\
\hline PBN & ZT3-ZT9 & 4 & $408 \pm 45$ & $<0.0001$ & 4 & $82 \pm 3$ & 0.9045 & 4 & $37.4 \pm 0.2$ & 0.8293 \\
\hline & ZT15-ZT21 & 4 & $144 \pm 13$ & & 4 & $80 \pm 3$ & & 4 & $37.6 \pm 0.2$ & \\
\hline
\end{tabular}

${ }^{1}$ PBN, $\alpha$-phenyl-butyl-tert-nitrone.

${ }^{2}$ Unless otherwise mentioned, analyses were done by two-way ANOVA followed by Tukey's multiple comparisons test.

hyperglycemia in the mice of the daytime group could explain the larger observed cerebral infarction in that study.

To further explore this phenomenon, we collected blood from mice during the daytime (ZT3-ZT9; sleep cycle for mice) and nighttime (ZT15-ZT21; awake cycle for mice), with or without acute hyperglycemia induced by glucose infusion, and subjected the mice to cerebral ischemia by dMCAO thereafter to reassess the effect of the circadian rhythm and blood glucose on ischemic infarction (Fig. 2A-F; Table 2). In the present study, mice in the daytime and nighttime groups had blood glucose concentrations of $165 \pm 12 \mathrm{mg} / \mathrm{dl}(n=13)$ and $139 \pm 11 \mathrm{mg} / \mathrm{dl}$ ( $n=11 ; p=0.5226$, daytime compared with nighttime, Tukey's multiple comparisons test), and mice that received a glucose infusion 20 min before blood collection had a blood glucose concentration of $302 \pm 22 \mathrm{mg} / \mathrm{dl}$ ( $n=13 ; p<0.0001$, glucose compared with no glucose, Tukey's multiple comparisons test; Fig. 2A; Table 2). In a subset of mice, we also determined blood glucose 60 min postischemia, and found that mice in the daytime and nighttime groups had blood glucose concentrations of $133 \pm 14 \mathrm{mg} / \mathrm{dl}(n=6)$ and $101 \pm 8 \mathrm{mg} / \mathrm{dl}(n=6 ; p=0.5515$, daytime compared with nighttime, Tukey's multiple comparisons test), and mice that received a glucose infusion $20 \mathrm{~min}$ before ischemia had a blood glucose concentration of $294 \pm 33 \mathrm{mg} / \mathrm{dl}(n=6) 60 \mathrm{~min}$ postischemia $(p<0.0001$, glucose compared with no glucose, Tukey's multiple comparisons test; Fig. 2B; Table 2). In light of overwhelming evidence for positive correlation between blood glucose and stroke severity in the clinic (Riddle and Hart, 1982; Pulsinelli et al., 1983; Candelise et al., 1985; Berger and Hakim, 1986; Weir et al., 1997; Capes et al., 2001; Williams et al., 2002), we did not observe a significant correlation between blood glucose of individual mice and their infarct volumes when each group of mice was assessed individually $(p=0.5332$ for mice in the daytime group; $p=0.2075$ for mice in the nighttime group; $p=0.7632$ for mice with glucose pretreatment), but did find marginal yet significant correlation between blood glucose of individual mice and their infarct volumes when the data from all mice were 
A



C 60 min postischemia

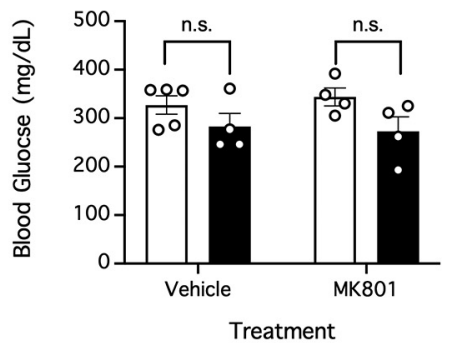

B

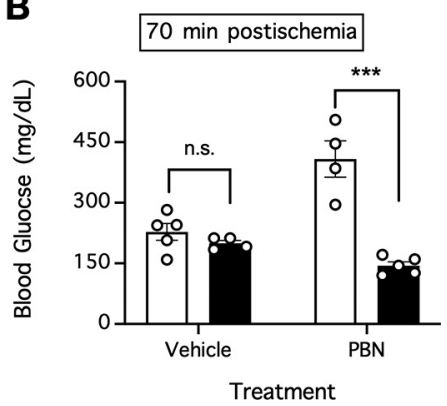

D

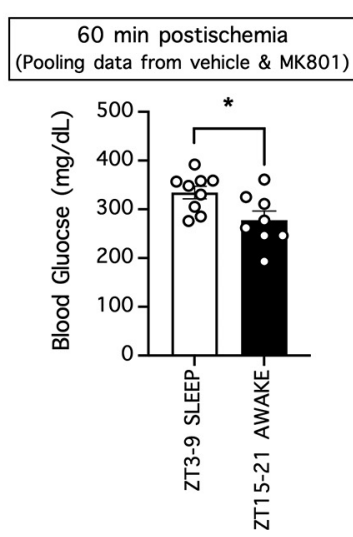

Figure 1. Blood glucose concentrations of the mice in the daytime groups versus the nighttime groups in the circadian stroke study (Esposito et al., 2020). $\boldsymbol{A}-\boldsymbol{C}$, We reanalyzed the source data to compare the blood glucose concentrations of mice in the daytime groups versus the nighttime groups published in that study. Blood was collected at $30 \mathrm{~min}(\boldsymbol{A}), 70 \mathrm{~min}(\boldsymbol{B})$, or $60 \mathrm{~min}(\boldsymbol{C})$ postischemia. In $\boldsymbol{A}-\boldsymbol{C}, n=4-6$ per group; ${ }^{\star} p<0.05,{ }^{* \star *} p<0.01$, two-way ANOVA followed by Tukey's multiple comparisons test; n.s. indicates no significant difference. $\boldsymbol{D}$, To increase statistical power for $\boldsymbol{C}$, we pulled the data from mice regardless of the treatment received and instead grouped the mice in accordance with phase of the circadian cycle. In $\boldsymbol{D}, n=8-9$ per group; ${ }^{*} p<0.05$, Student's $t$ test. PBN, $\alpha$-phenyl-butyl-tert-nitrone.

pooled $\left(r^{2}=0.2004\right.$ and $p=0.0116$; Fig. 2C; Table 3). With Tukey's multiple comparisons test, we found that mice in the daytime and nighttime groups had infarction volumes of $7 \pm 1 \mathrm{~mm}^{3}(n=11)$ and $8 \pm 1 \mathrm{~mm}^{3}(n=10 ; p=0.9851$, daytime compared with nighttime), and mice that received a glucose infusion 20 min before cerebral ischemia had an infarction volume of $22 \pm 6 \mathrm{~mm}^{3}(n=10 ; p=0.0352$, glucose compared with no glucose; Fig. $2 D, F$; Table 2). When the infarct volume were normalized to account for potential cerebral edema, mice in the daytime and nighttime groups had infarction volumes of $6 \pm 1 \mathrm{~mm}^{3}(n=11)$ and $8 \pm 1$ $\mathrm{mm}^{3}(n=10 ; p=0.8985$, daytime compared with nighttime), and mice that received a glucose infusion $20 \mathrm{~min}$ before cerebral ischemia had an infarction volume of $23 \pm 6$ $\mathrm{mm}^{3}$ ( $n=10 ; p=0.0116$, glucose compared with no glucose; Fig. 2E,F; Table 2). Therefore, our data suggested that the blood glucose concentration rather than the circadian phase during which stroke occurred exacerbates stroke severity.

\section{Effect of MK801 on stroke severity in hyperglycemic mice}

With our new analysis and data, we next asked whether a larger stroke infarction volume caused by hyperglycemia would be subject to neuroprotection by MK801 in a preclinical dMCAO stroke model that is otherwise well established to be resistant to neuroprotection by MK801 under normoglycemic conditions (Liu et al., 2020, 2021). Surprisingly, we found that the opposite was true (Fig. 3A$E ;$ Table 2). To induce acute hyperglycemia, we infused mice with glucose $20 \mathrm{~min}$ before the induction of cerebral ischemia, and collected blood for analysis immediately before ischemia onset. Unexpectedly, pretreatment of these mice with MK801 60 min before ischemia onset further exacerbated their hyperglycemia $(370 \pm 19 \mathrm{mg} / \mathrm{dl} ; n=12$; $p=0.0289, t$ test) compared with that of saline-treated hyperglycemic mice (311 $\pm 17 \mathrm{mg} / \mathrm{dl} ; n=12$; Fig. $3 A$; Table 2). Consistent with the exacerbated hyperglycemia and the effect that blood glucose is known to have on stroke severity, MK801 also increased stroke infarction volume in hyperglycemic mice $\left(23 \pm 4 \mathrm{~mm}^{3} ; n=11 ; p=0.0363, t\right.$ test) compared with that in hyperglycemic mice treated with saline $\left(14 \pm 2 \mathrm{~mm}^{3} ; n=11\right.$; Fig. 3B,E; Table 2). When the infarct volumes were normalized to account for potential cerebral edema, MK801 increased normalized infarction volumes in hyperglycemic mice $\left(23 \pm 4 \mathrm{~mm}^{3} ; n=11 ; p=0.0075, t\right.$ test $)$ compared with those in hyperglycemic mice treated with saline (12 $\pm 1 \mathrm{~mm}^{3} ; n=11$; Fig. $3 C, E$; Table 2). Perhaps because of our small sample sizes, in contrast to expectations from clinical data (Riddle and Hart, 1982; Pulsinelli et al., 1983; Candelise et al., 1985; Berger and Hakim, 1986; 



C

Figure 2
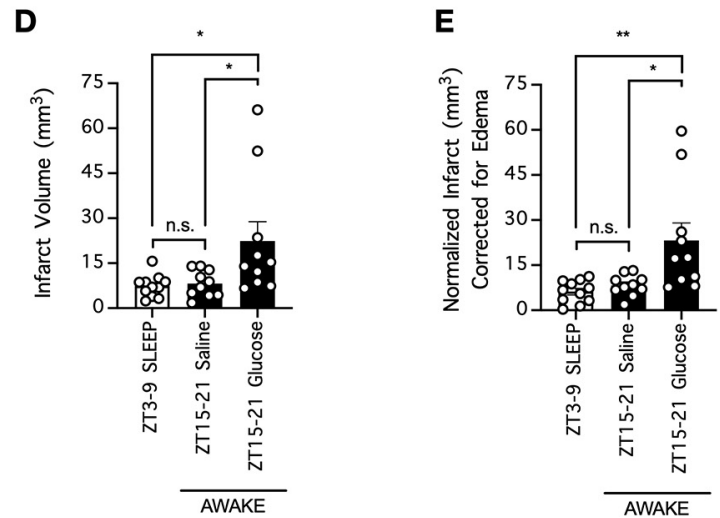

$\mathbf{F}$

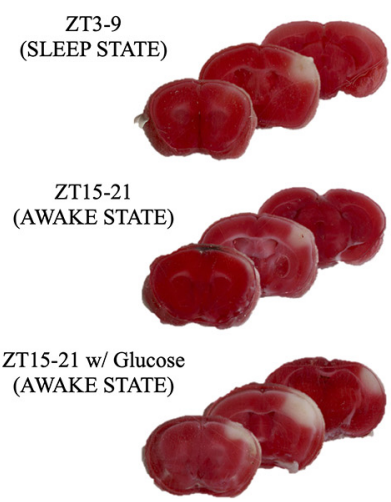

Figure 2. Hyperglycemia rather than the circadian phase during which stroke occurs determines the ischemic infarction volume. $\boldsymbol{A}$, Blood was collected to measure blood glucose concentrations from mice in the daytime group (ZT3-ZT9; sleep cycle for mice) or the nighttime group (ZT15-ZT21; awake cycle for mice), the latter group received either a saline or glucose injection (2.2 g/kg, i.p.) 20 min before blood collection; $n=11-13$ per group. $\boldsymbol{B}$, Blood was also collected 60 min postischemia in a subset of mice in $\boldsymbol{A}$; $n=6$ per group. In $\boldsymbol{A}, \boldsymbol{B},{ }^{\star \star \star} p<0.001$, one-way ANOVA followed by Tukey's multiple comparisons test; n.s. indicates no significant difference. $\boldsymbol{C}, \boldsymbol{D}$, The mice from $\boldsymbol{A}$ underwent cerebral ischemia induction by dMCAO immediately following blood collection, and the ischemic infarction volume was assessed $24 \mathrm{~h}$ postischemia. Data were analyzed by linear regression (C) or one-way ANOVA followed by Tukey's multiple comparisons test $(\boldsymbol{D})$. $\boldsymbol{E}$, Same as $\boldsymbol{D}$, except infarct was normalized to account for potential brain edema. In $\boldsymbol{D}, \boldsymbol{E}, n=10-11$ per group; ${ }^{*} p<0.05$, ${ }^{\star *} p<0.01$, one-way ANOVA followed by Tukey's multiple comparisons test; n.s. indicates no significant difference. $\boldsymbol{F}$, Representative images of coronal brain sections of mice from $\boldsymbol{C}, \boldsymbol{D}$. Functional brain tissue was stained red by TTC, and the infarct area remained pale white and unstained.

Weir et al., 1997; Capes et al., 2001; Williams et al., 2002), we did not find significant correlation between blood glucose of individual mice and their infarct volumes $(p>0.05$; Fig. 3D; Table 3). Taken together, our data demonstrated that hyperglycemia did not promote the neuroprotective effect of MK801 in the preclinical stroke model. Instead, they raised the intriguing possibility that one of the reasons for the clinical failure of NMDAR antagonism is because of a potential exacerbating effect of NMDAR antagonists on stroke outcome in hyperglycemic patients.

\section{Uncompetitive NMDAR antagonist increases blood glucose in normoglycemic mice}

To examine whether MK801 would have a similar effect on blood glucose in normoglycemic mice and to identify the type of NMDAR antagonists that would have such an effect, we injected normoglycemic mice with three different types of NMDAR antagonists: (1) AP5, a competitive antagonist that is blood-brain barrier (BBB)-impermeable; (2) MK801, an uncompetitive antagonist that is BBB-permeable; and (3) CPP, a competitive antagonist that is BBB-permeable; we then collected blood $40 \mathrm{~min}$ postinjection to assess the effect of these drugs on blood glucose (Fig. 4A, $B$; Table 2). Blood glucose concentrations before injection were $178 \pm 12 \mathrm{mg} / \mathrm{dl}(n=7)$ in the saline group, $193 \pm$ $10 \mathrm{mg} / \mathrm{dll}(n=7)$ in the AP5 group, $191 \pm 8 \mathrm{mg} / \mathrm{dl}(n=7)$ in the MK801 group, and $190 \pm 17 \mathrm{mg} / \mathrm{dl}(n=6)$ in the CPP group; there was no significant difference between different groups $(p>0.05$, Tukey's multiple comparisons test; Fig. 4B). After injection of the respective antagonists in normoglycemic mice, blood glucose concentrations were $175 \pm 9 \mathrm{mg} / \mathrm{dl}(n=7)$ in the saline group, $192 \pm$ $17 \mathrm{mg} / \mathrm{dl}(n=7)$ in the AP5 group, $223 \pm 10 \mathrm{mg} / \mathrm{dl}(n=7)$ in the MK801 group, and $195 \pm 18 \mathrm{mg} / \mathrm{dl}(n=6)$ in the CPP group; importantly, MK801, but not AP5 $(p=$ 0.7902 , compared with saline group, Tukey's multiple comparisons test) or CPP ( $p=0.7456)$, significantly increased 
Table 2: Group comparisons analysis of data from this study

\begin{tabular}{|c|c|c|c|c|}
\hline & & $N$ & Mean \pm SEM & $p$ value \\
\hline Figure 2 & \multicolumn{4}{|c|}{ One-way ANOVA followed by Tukey's multiple comparisons test } \\
\hline \multirow[t]{3}{*}{$2 A$} & ZT3-ZT9 SLEEP & 13 & $165 \pm 12$ & 0.5226 , daytime compared with nighttime \\
\hline & ZT15-ZT21 saline & 11 & $139 \pm 11$ & \\
\hline & ZT15-ZT21 glucose & 13 & $302 \pm 22$ & $<0.0001$, glucose compared with no glucose \\
\hline \multirow[t]{3}{*}{$2 B$} & ZT3-ZT9 SLEEP & 6 & $133 \pm 14$ & 0.5515 , daytime compared with nighttime \\
\hline & ZT15-ZT21 saline & 6 & $101 \pm 8$ & \\
\hline & ZT15-ZT21 glucose & 6 & $294 \pm 33$ & $<0.0001$, glucose compared with no glucose \\
\hline \multirow[t]{3}{*}{$2 D$} & ZT3-ZT9 SLEEP & 11 & $7 \pm 1$ & 0.9851 , daytime compared with nighttime \\
\hline & ZT15-ZT21 saline & 10 & $8 \pm 1$ & \\
\hline & ZT15-ZT21 glucose & 10 & $22 \pm 6$ & 0.0352 , glucose compared with no glucose \\
\hline \multirow[t]{3}{*}{$2 E$} & ZT3-ZT9 SLEEP & 11 & $6 \pm 1$ & 0.8985 , daytime compared with nighttime \\
\hline & ZT15-ZT21 saline & 10 & $8 \pm 1$ & \\
\hline & ZT15-ZT21 glucose & 10 & $23 \pm 6$ & 0.0116, glucose compared with no glucose \\
\hline Figure 3 & Unpaired $t$ test & & & \\
\hline \multirow[t]{2}{*}{$3 A$} & Glucose + saline & 12 & $311 \pm 17$ & 0.0289 \\
\hline & Glucose + MK801 & 12 & $370 \pm 19$ & \\
\hline \multirow[t]{2}{*}{$3 B$} & Glucose + saline & 11 & $14 \pm 2$ & 0.0363 \\
\hline & Glucose + MK801 & 11 & $23 \pm 4$ & \\
\hline \multirow[t]{2}{*}{$3 c$} & Glucose + saline & 11 & $12 \pm 1$ & 0.0075 \\
\hline & Glucose + MK801 & 11 & $23 \pm 4$ & \\
\hline Figure 4 & \multicolumn{4}{|c|}{$\begin{array}{l}\text { Two-way repeated-measures ANOVA matching blood glucose from the same animal, which was } \\
\text { followed by Tukey's multiple comparisons test }\end{array}$} \\
\hline \multirow[t]{4}{*}{ Baseline } & Saline & 7 & $178 \pm 12$ & $>0.05$, compared with saline group \\
\hline & AP5 & 7 & $193 \pm 10$ & \\
\hline & MK801 & 7 & $191 \pm 8$ & \\
\hline & CPP & 6 & $190 \pm 17$ & \\
\hline \multirow[t]{4}{*}{ Post-NMDAR blocker } & Saline & 7 & $175 \pm 9$ & \\
\hline & AP5 & 7 & $192 \pm 17$ & 0.7902 , compared with saline group \\
\hline & MK801 & 7 & $223 \pm 10$ & 0.0163, compared with saline group \\
\hline & CPP & 6 & $195 \pm 18$ & 0.7456 , compared with saline group \\
\hline \multirow[t]{4}{*}{ Postglucose } & Saline & 7 & $345 \pm 9$ & \\
\hline & AP5 & 7 & $334 \pm 25$ & 0.9746, compared with saline group \\
\hline & MK801 & 7 & $434 \pm 10$ & $<0.0001$, compared with saline group \\
\hline & CPP & 6 & $372 \pm 11$ & 0.2813, compared with saline group \\
\hline Figure 5 & Unpaired $t$ test & & & \\
\hline \multirow[t]{2}{*}{$5 A$} & Glucose + saline & 19 & $299 \pm 13$ & 0.0005 \\
\hline & Glucose + ketamine & 18 & $380 \pm 17$ & \\
\hline \multirow[t]{2}{*}{$5 B$} & Glucose + saline & 16 & $8 \pm 1$ & 0.0446 \\
\hline & Glucose + ketamine & 16 & $15 \pm 3$ & \\
\hline \multirow[t]{2}{*}{$5 C$} & Glucose + saline & 16 & $9 \pm 1$ & 0.0217 \\
\hline & Glucose + ketamine & 16 & $16 \pm 3$ & \\
\hline Figure 6 & Unpaired $t$ test & & & \\
\hline \multirow[t]{2}{*}{$6 A$} & Diabetic + saline & 9 & $290 \pm 13$ & 0.0001 \\
\hline & Diabetic + MK801 & 9 & $403 \pm 18$ & \\
\hline \multirow[t]{2}{*}{$6 B$} & Diabetic + saline & 9 & $8 \pm 2$ & 0.0454 \\
\hline & Diabetic + MK801 & 9 & $18 \pm 4$ & \\
\hline \multirow[t]{2}{*}{$6 C$} & Diabetic + saline & 9 & $8 \pm 2$ & 0.0469 \\
\hline & Diabetic + MK801 & 9 & $18 \pm 4$ & \\
\hline
\end{tabular}

blood glucose in normoglycemic mice ( $p=0.0163$; Fig. $4 B$ ). To examine whether different types of NMDAR antagonists would similarly influence blood glucose in a hyperglycemic state, the above mice were further infused with glucose, and their blood was collected $20 \mathrm{~min}$ later to measure blood glucose concentrations (Fig. 4A,B; Table 2). The blood glucose concentrations after glucose infusion were $345 \pm 9 \mathrm{mg} / \mathrm{dl}$ $(n=7)$ in the saline group, $334 \pm 25 \mathrm{mg} / \mathrm{dl}(n=7)$ in the AP5 group, $434 \pm 10 \mathrm{mg} / \mathrm{dl}(n=7)$ in the MK801 group, and $372 \pm 11 \mathrm{mg} / \mathrm{dl}(n=6)$ in the CPP group; therefore, MK801, but not AP5 $(p=0.9746$, compared with saline group, Tukey's multiple comparisons test) or CPP $(p=0.2813)$, significantly increased blood glucose in hyperglycemic mice $(p<0.0001$; Fig. $4 B)$. Thus, our data demonstrate that an uncompetitive NMDAR antagonist such as MK801 increases blood glucose in both normoglycemic and hyperglycemic mice. In contrast, competitive antagonists of NMDARs have no effect on blood glucose in either normoglycemic or hyperglycemic mice.

\section{Ketamine increases blood glucose and exacerbates stroke infarct in hyperglycemic mice}

To validate that the effect of MK801 on blood glucose and stroke severity was because of its pharmacological property as an NMDAR uncompetitive antagonist, we 
Table 3: Linear regression analysis of data from this study

\begin{tabular}{|c|c|c|c|c|}
\hline Figures & & $N$ & Goodness of fit $\left(R^{2}\right)$ & $p$ value (significance of correlation) \\
\hline \multirow[t]{2}{*}{$2 \mathrm{C}$} & ZT3-ZT9 SLEEP & 11 & 0.04456 & 0.5332 \\
\hline & ZT15-ZT21 glucose & 10 & 0.01200 & 0.7632 \\
\hline \multirow[t]{3}{*}{$3 D$} & Glucose + saline & 11 & 0.05862 & 0.4732 \\
\hline & Glucose + MK801 & 11 & 0.03878 & 0.5616 \\
\hline & Pooled & 22 & 0.01671 & 0.5664 \\
\hline $5 D$ & Pooled & 32 & 0.02799 & 0.3601 \\
\hline \multirow[t]{3}{*}{$6 D$} & Diabetic + saline & 9 & 0.0006287 & 0.9489 \\
\hline & Diabetic + MK801 & 9 & 0.1605 & 0.2853 \\
\hline & Pooled & 18 & 0.04701 & 0.3875 \\
\hline
\end{tabular}

tested whether ketamine, another NMDAR uncompetitive antagonist, would have similar effects. Mice were injected with ketamine 60 min before ischemia onset and then injected with glucose 20 min before ischemia onset to achieve a hyperglycemic state; thereafter, blood was collected to measure the blood glucose concentration immediately before ischemia onset. Ketamine strongly increased the blood glucose concentration of these mice to $380 \pm 17 \mathrm{mg} / \mathrm{dl}(n=18)$ compared with saline-treated mice, which had a blood glucose concentration of $299 \pm 13 \mathrm{mg} / \mathrm{dl}(n=19 ; p=0.0005, t$ test; Fig. 5A; Table 2). In addition, $24 \mathrm{~h}$ after induction of cerebral ischemia by dMCAO, ketamine-treated mice had a larger ischemic infarction of $15 \pm 3 \mathrm{~mm}^{3}(n=16)$ than saline-treated mice, which had an ischemic infarction of $8 \pm 1 \mathrm{~mm}^{3}(n=16$; $p=0.0446$, $t$ test; Fig. 5B,E; Table 2). When the infarct volume were normalized to account for potential cerebral edema, ketamine-treated mice had a larger normalized infarction of $16 \pm 3 \mathrm{~mm}^{3}(n=16)$ than saline-treated mice, which had an normalized infarction of $9 \pm 1 \mathrm{~mm}^{3}(n=16 ; p=0.0217, t$ test; Fig. 5C,E; Table 2). Nevertheless, with our small sample sizes, we did not find significant correlation between blood glucose of individual mice and their infarct volumes $(p>0.05$; Fig. 5D; Table 3). Therefore, similar to MK801, ketamine exacerbates hyperglycemia in mice and worsens stroke outcome.

\section{MK801 increases blood glucose and exacerbates stroke infarct in diabetic mice}

To better address whether the effect of NMDAR uncompetitive antagonist on blood glucose and stroke severity might be clinically relevant, we tested whether MK801 would have a similar effect in a mouse model of diabetes mellitus. Mice were rendered diabetic by STZ injections more than a week before the experiment (STZ-resistant mice were excluded; Table 4), and were injected with MK801 60 min before cerebral ischemia by dMCAO. When blood was collected for analysis immediately before ischemia onset, MK801 increased the blood glucose concentration of these diabetic mice to $403 \pm 18 \mathrm{mg} / \mathrm{dl}(n=9)$ compared with salinetreated diabetic mice, which had a blood glucose concentration of $290 \pm 13 \mathrm{mg} / \mathrm{dl}(n=9 ; p=0.0001$, $t$ test; Fig. 6 A; Table 2). Consistent with the exacerbated hyperglycemia, MK801treated diabetic mice had a larger ischemic infarction of $18 \pm 4$ $\mathrm{mm}^{3}(n=9)$ than saline-treated diabetic mice, which had an ischemic infarction of $8 \pm 2 \mathrm{~mm}^{3}(n=9 ; p=0.0454, t$ test; Fig. $6 B, E ;$ Table 2). When the infarct volume were normalized to account for potential cerebral edema, MK801-treated diabetic mice had a larger normalized infarction of $18 \pm 4 \mathrm{~mm}^{3}(n=9)$ than saline-treated diabetic mice, which had a normalized infarction of $8 \pm 2 \mathrm{~mm}^{3}(n=9 ; p=0.0469, t$ test; Fig. $6 C, E$; Table 2). However, with our small sample sizes, we did not find significant correlation between blood glucose of individual mice and their infarct volumes ( $p>0.05$; Fig. 6D; Table 3). Taken together, our data showed that MK801 exacerbates hyperglycemia in diabetic mice and worsens stroke outcome.

\section{Discussion}

NMDARs are a widely sought-after therapeutic target for the development of stroke treatments (Lai et al., 2014).

Table 4: Mice excluded from cerebral infarct analysis

\begin{tabular}{lllll}
\hline Figures & & $N$ & Reason for exclusion & Blood glucose concentrations \\
\hline 2 & ZT3-ZT9 SLEEP & 2 & $1 \times$ Died during surgery & 168,135 \\
& & & $1 \times$ Died after reperfusion & 187 \\
& ZT15-ZT21 saline & 1 & $1 \times$ Died after reperfusion & $238,306,301$ \\
& ZT15-ZT21 glucose & 3 & $2 \times$ Died during surgery & 279 \\
3 & Glucose + saline & 1 & $1 \times$ Died after reperfusion & 379 \\
& Glucose + MK801 & 1 & $1 \times$ Died during surgery & $287,229,332$ \\
5 & Glucose + saline & 3 & $2 \times$ Died during surgery & 403,415 \\
6 & & & $1 \times$ Died after reperfusion & $186,172,188,165$ \\
Total & Glucose + ketamine & 2 & $2 \times$ Died during surgery & \\
\end{tabular}


A

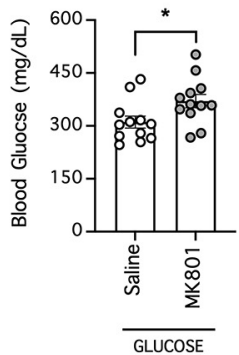

D

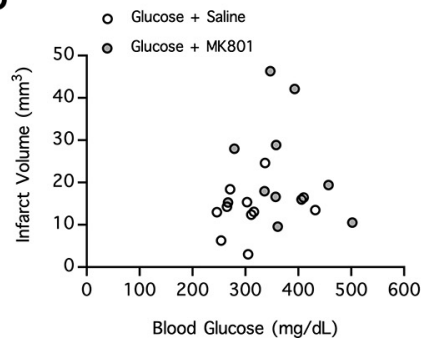

B



C

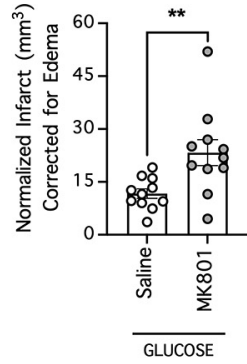

E
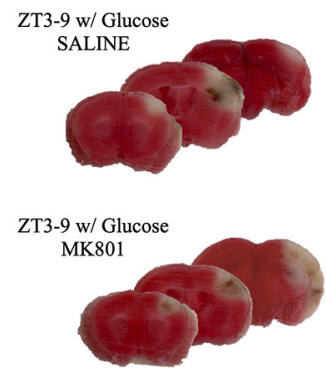

Figure 3. MK801 increases blood glucose and the ischemic infarction volume in hyperglycemic mice in which stroke was induced. $\boldsymbol{A}$, Blood was collected to measure the blood glucose concentrations of hyperglycemic mice pretreated with either saline or MK801 $(4 \mathrm{mg} / \mathrm{kg}$, i.p.) in the daytime group (ZT3-ZT9; sleep cycle for mice). Saline or MK801 was administered $60 \mathrm{~min}$ before blood collection, and mice were rendered hyperglycemic by a glucose injection $(2.2 \mathrm{~g} / \mathrm{kg}$, i.p.) $20 \mathrm{~min}$ before blood collection; $n=12 \mathrm{per}$ group. $\boldsymbol{B}$, The mice from $\boldsymbol{A}$ underwent cerebral ischemia induction by dMCAO immediately following blood collection, and the ischemic infarction volume was assessed $24 \mathrm{~h}$ postischemia; $n=11$ per group. $\boldsymbol{C}$, Same as $\boldsymbol{B}$, except infarct was normalized to account for potential brain edema; $n=11$ per group. In $\boldsymbol{A}-\boldsymbol{C},{ }^{*} p<0.05,{ }^{\star \star} p<0.01$, Student's $t$ test. $\boldsymbol{D}, \mathrm{XY}$ plot of data from $\boldsymbol{A}, \boldsymbol{B}$. $\boldsymbol{E}$, Representative images of coronal brain sections of mice from $\boldsymbol{B}$. Functional brain tissue was stained red by TTC, and the infarct area remained pale white and unstained.

Decades of experimental evidence have suggested that during stroke, a dramatic increase in extracellular glutamate causes excessive stimulation of NMDARs; consequently, opening of the NMDAR channel pore leads to calcium ion influx into ischemic neurons. Calcium ions then trigger the release of nitrogen and oxygen free radicals, as well as other neuronal death-signaling cascades, to cause stroke injury. Therefore, drugs that inhibit

A Experimental Timeline

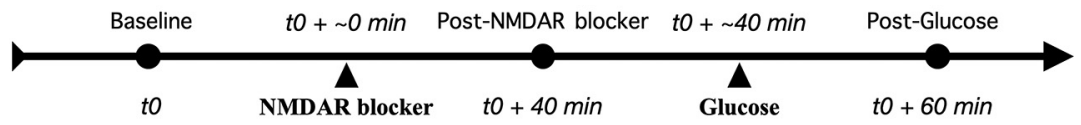

B

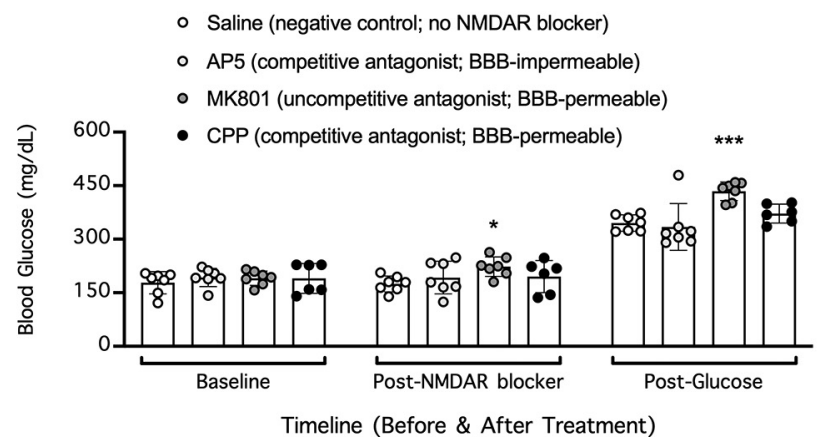

Figure 4. Uncompetitive but not competitive antagonists of the NMDAR increase blood glucose in normoglycemic and hyperglycemic mice. $\boldsymbol{A}$, Experimental timeline. Blood was collected before any treatments (baseline) and 40 min after injection of NMDAR antagonists: AP5 (10 mg/kg, i.p.), MK801 (4 mg/kg, i.p.), or CPP (10 mg/kg, i.p.); thereafter, the mice received a glucose injection $(2.2 \mathrm{~g} / \mathrm{kg}$, i.p.) to induce hyperglycemia, and blood was once again collected $20 \mathrm{~min}$ after glucose injection. $\boldsymbol{B}$, Glucose concentrations of blood collected as described in $\boldsymbol{A} ; n=6-7$ per group; ${ }^{*} p<0.05$, ${ }^{* * *} p<0.001$, one-way repeated-measures ANOVA, matching blood collected from the same mouse, followed by Tukey's multiple comparisons test. 


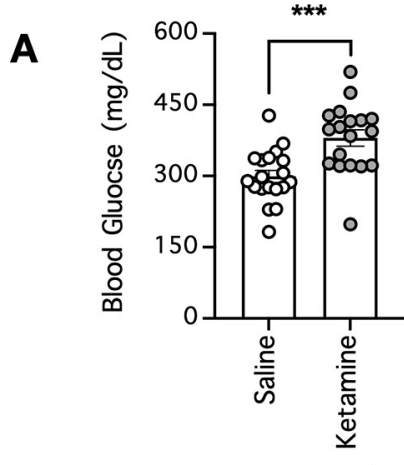

GLUCOSE



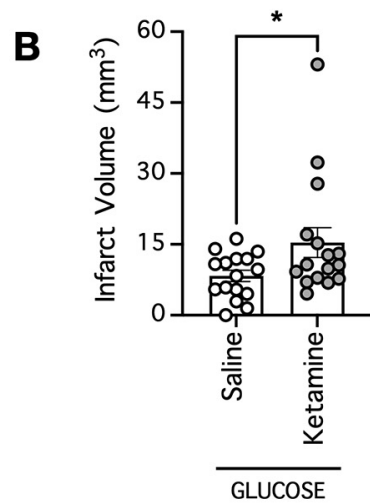

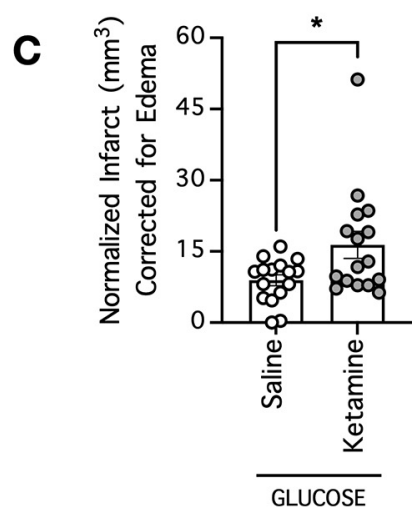

E
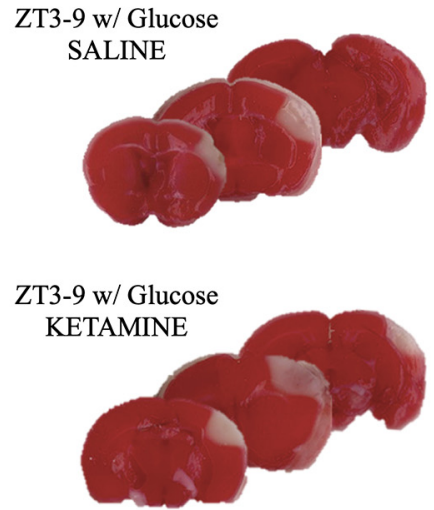

Figure 5. Ketamine increases blood glucose and the ischemic infarction volume in hyperglycemic mice subjected to stroke. $\boldsymbol{A}$, Blood was collected to measure the blood glucose concentrations of hyperglycemic mice pretreated with either saline or ketamine (10 mg/kg, i.p.) in the daytime group (ZT3-ZT9; sleep cycle for mice). Saline or ketamine was administered $60 \mathrm{~min}$ before blood collection, and mice were rendered hyperglycemic by a glucose injection ( $2.2 \mathrm{~g} / \mathrm{kg}$, i.p.) 20 min before blood collection; $n=18-19$ per group. $\boldsymbol{B}$, The mice from $\boldsymbol{A}$ underwent cerebral ischemia induction by dMCAO immediately following blood collection, and the ischemic infarction volume was determined $24 \mathrm{~h}$ postischemia; $n=16$ per group. $\boldsymbol{C}$, Same as $\boldsymbol{B}$, except infarct was normalized to account for potential brain edema; $n=16$ per group. In $\boldsymbol{A}-\boldsymbol{C},{ }^{*} p<0.05$, ${ }^{* \star *} p<0.001$, Student's $t$ test. $\boldsymbol{D}$, XY plot of data from $\boldsymbol{A}, \boldsymbol{B}$. $\boldsymbol{E}$, Representative images of coronal brain sections of mice from $\boldsymbol{B}$. Functional brain tissue was stained red by TTC, and the infarct area remained pale white and unstained.

NMDARs or the NMDAR-mediated release of free radicals have been tested in preclinical animal models in the hope that they will be beneficial to stroke patients in the clinic. These include competitive antagonists, such as AP5 and CPP, which directly bind to glutamate-binding sites on NMDARs; uncompetitive antagonists, such as MK801 and ketamine, which block the NMDAR channel pore when the receptors are activated such that calcium influx cannot occur even when the receptors are activated; and drugs that interfere with the NMDAR-mediated release of free radicals, such as NA-1 or $\alpha$-phenyl-butyl-tert-nitrone, which do not inhibit NMDARs directly but interfere with NMDAR-mediated neuronal injury. Although these drugs are neuroprotective in many animal models of stroke, none have proven to be successful in stroke clinical trials (Lai et al., 2014; Hill et al., 2020).

Several reasons why NMDAR antagonists failed clinical trials have been postulated and have been extensively reviewed by our laboratory (Lai et al., 2014). Notably, these drugs are neuroprotective in only some animal models of cerebral ischemia (McDonald et al., 1987; Ozyurt et al.,
1988; Park et al., 1988a, b; Ikonomidou et al., 1989; Olney et al., 1989; Rod and Auer, 1989; Rod et al., 1990; Swan and Meldrum, 1990; Gill et al., 1991; Buchan et al., 1992; Hatfield et al., 1992; Lo et al., 1994; Margaill et al., 1996; Ma et al., 1998) and not in others (Buchan et al., 1991; LeBlanc et al., 1991; Nellgård et al., 1991; Nellgård and Wieloch, 1992; Liu et al., 2020, 2021). Even in the same animal model of cerebral ischemia, the neuroprotective efficacy of NMDAR antagonists might be contingent on the specific experimental condition or condition of the animal during the experiment, such as their body temperature (Ikonomidou et al., 1989; Buchan and Pulsinelli, 1990; Corbett et al., 1990; Warner et al., 1991; Memezawa et al., 1995; Alkan et al., 2001; Gerriets et al., 2003). In the present study, we further demonstrate that uncompetitive NMDAR antagonists, including MK801 and ketamine, can exacerbate stroke outcome by increasing blood glucose in hyperglycemic mice. Therefore, given the high prevalence of hyperglycemia among stroke patients (Scott et al., 1999; Williams et al., 2002), we recommend that future clinical trials testing uncompetitive 
A

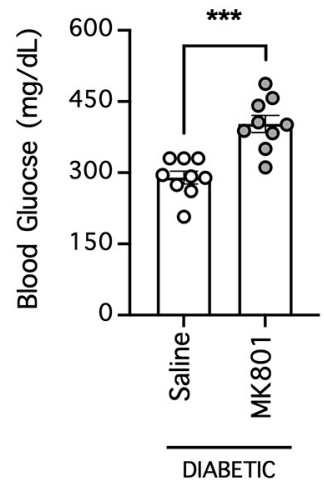

D

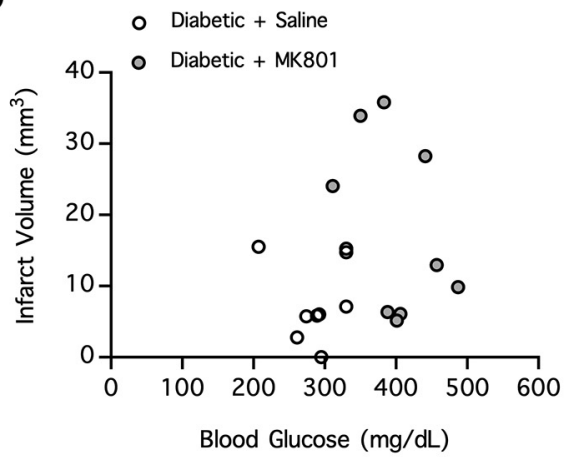

B

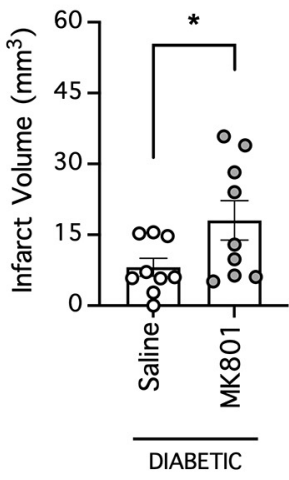

C

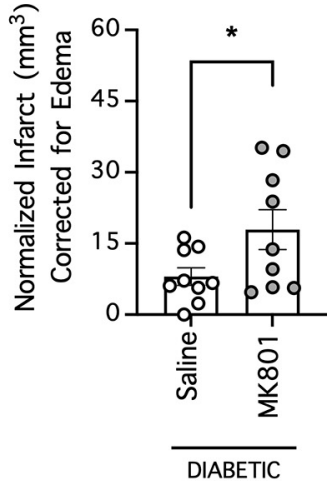

E

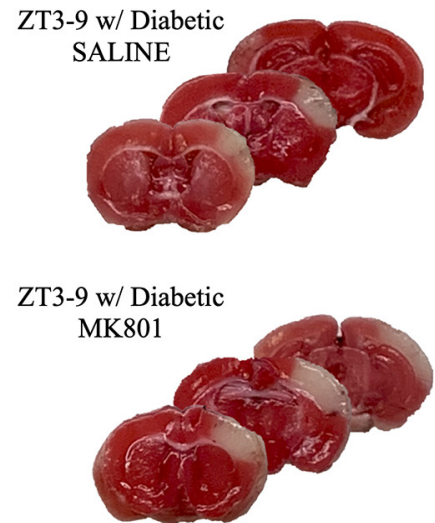

Figure 6. MK801 increases blood glucose and the ischemic infarction volume in diabetic mice subjected to stroke. $\boldsymbol{A}$, Mice were subjected to repeated STZ injections initiated two weeks before cerebral ischemia to induce diabetes mellitus. Blood was collected to measure the blood glucose concentrations of diabetic mice 60 min after pretreatment with either saline or MK801 (4 mg/kg, i.p.) in the daytime group (ZT3-ZT9; sleep cycle for mice); $n=9$ per group. $\boldsymbol{B}$, The mice from $\boldsymbol{A}$ underwent cerebral ischemia induction by dMCAO immediately following blood collection, and the ischemic infarction volume was determined $24 \mathrm{~h}$ postischemia; $n=9$ per group. $\boldsymbol{C}$, Same as $\boldsymbol{B}$, except infarct was normalized to account for potential brain edema; $n=9$ per group. In $\boldsymbol{A}-\boldsymbol{C},{ }^{*} p<0.05,{ }^{* * *} p<0.001$, Student's $t$ test. $\boldsymbol{D}, \mathrm{XY}$ plot of data from $\boldsymbol{A}, \boldsymbol{B}$. $\boldsymbol{E}$, Representative images of coronal brain sections of mice from $\boldsymbol{B}$. Functional brain tissue was stained red by TTC, and the infarct area remained pale white and unstained.

NMDAR antagonists preemptively measure blood glucose concentrations and exclude stroke patients who are moderately hyperglycemic from participating in the trial. Such a measure would maximize clinical trial success and avoid unnecessary risk for stroke patients participating in the trial.

The mechanism by which blood glucose exacerbates stroke outcome seems to be multifactorial and involves an increased likelihood of ischemia-induced seizure (Siemkowicz and Hansen, 1978), an impairment of postischemic cerebral blood flow (Ginsberg et al., 1980), augmented lactic acidosis (Welsh et al., 1980), and worsened ischemia-induced BBB disruption (Dietrich et al., 1993). In addition to smaller mammals (Siemkowicz and Hansen, 1978; Siemkowicz, 1981; Pulsinelli et al., 1982; de Courten-Myers et al., 1988, 1994; Yip et al., 1991), juvenile monkeys exhibited exacerbated ischemic brain damage following glucose administration (Myers and Yamaguchi, 1977), and blood glucose concentrations have consistently been correlated with worse stroke outcome in the clinic (Riddle and Hart, 1982; Pulsinelli et al., 1983; Candelise et al., 1985; Berger and Hakim, 1986; Weir et al., 1997; Capes et al., 2001; Williams et al., 2002). Notably, although an acute increase in blood glucose can exacerbate stroke severity, therapeutically decreasing blood glucose does not necessarily improve outcome in animals subjected to cerebral ischemia (Siemkowicz and Hansen, 1978; de Courten-Myers et al., 1994) or in stroke patients in clinical trials (Gray et al., 2007; Johnston et al., 2019).

Recently, one prominent study reported that the circadian phase during which stroke occurs can explain the translational failure of neuroprotective agents, including MK801 and $\alpha$-phenyl-butyl-tert-nitrone (Esposito et al., 2020). The authors found that mice that had ischemic stroke during their sleep cycle (daytime for mice; nighttime for humans) had larger cerebral infarctions and benefited from neuroprotective agents, whereas mice that had ischemic stroke during their wake cycle had a smaller 
infarction and these drugs failed to show any neuroprotection. Because clinical trials typically enroll patients who had a stroke during the daytime (human wake cycle), the findings of this study might explain the translational failure of neuroprotective agents (Esposito et al., 2020). In this study, mice subjected to cerebral ischemia induced by dMCAO had similar infarct volume regardless of the circadian phase during which stroke occurs. Moreover, when stroke infarct was increased by induction of hyperglycemia, NMDAR uncompetitive antagonists like MK801 or ketamine did not offer neuroprotection; rather, these drugs increased ischemic infarction volumes by exacerbating preexisting hyperglycemia. One caveat in our study is that we experimented with only one model of cerebral ischemia and used only male mice, and therefore, we cannot exclude the possibility that the circadian phase during which stroke occurs can have an effect in female, in other models of cerebral ischemia, including the models used in the previous circadian study (Esposito et al., 2020), or in other physiological and comorbid states. Nevertheless, our data show conclusively that cerebral ischemia occurring in the daytime do not necessarily translate into larger infarction.

Because of the differences in the mechanism by which they antagonize NMDARs, competitive antagonists such as AP5 and CPP and uncompetitive antagonists such as MK801 and ketamine are known to exert different overall pharmacological effects (Willetts et al., 1990). For example, AP5 but not MK801 inhibits temporary memory storage in a delay-dependent manner (Tonkiss and Rawlins, 1991). Likewise, AP5 but not MK801 inhibits glutamatedependent metabotropic NMDAR functions, including low-frequency stimulation and $\beta$-amyloid-induced synaptic depression (Kessels et al., 2013; Nabavi et al., 2013) and NMDAR-mediated dendritic blebbing and delayed inward current (Weilinger et al., 2016). Moreover, competitive but not uncompetitive antagonists of NMDARs block glycine-mediated neuroprotection in vitro and in vivo ( $\mathrm{Hu}$ et al., 2016; Chen et al., 2017). On the other hand, uncompetitive but not competitive antagonists of NMDARs are effective in increasing brain glucose and dopamine metabolism (Boddeke et al., 1992; Bubser et al., 1992) and are liable to become substances of abuse in accordance with self-administration studies in animals (Willetts et al., 1990). Unfortunately, in most cases, the exact reason why different classes of antagonists confer distinct pharmacological effects is not completely understood. In this study, we further showed that uncompetitive but not competitive antagonists of NMDARs increase blood glucose concentrations in normoglycemic and hyperglycemic mice, which could help partly explain the clinical failure of this class of NMDAR antagonists in stroke trials. The hyperglycemic effect of uncompetitive antagonists could also partly explain why only this class of NMDAR blockers can increase brain glucose metabolism.

In conclusion, we showed in this study that the circadian phase during which stroke occurs does not necessarily affect ischemic infarction. Moreover, uncompetitive antagonists of NMDARs, including MK801 and ketamine, increase blood glucose in normoglycemic and hyperglycemic mice, and this can result in exacerbated stroke outcome in hyperglycemic mice. Given that hyperglycemia is present in $\sim 60-80 \%$ of stroke patients, our finding likely explains the translational failure of this class of NMDAR antagonists from bench to clinic.

\section{References}

Alkan T, Kahveci N, Buyukuysal L, Korfali E, Ozluk K (2001) Neuroprotective effects of MK 801 and hypothermia used alone and in combination in hypoxic-ischemic brain injury in neonatal rats. Arch Physiol Biochem 109:135-144.

Berger L, Hakim AM (1986) The association of hyperglycemia with cerebral edema in stroke. Stroke 17:865-871.

Boddeke HW, Wiederhold KH, Palacios JM (1992) Intracerebroventricular application of competitive and non-competitive NMDA antagonists induce similar effects upon rat hippocampal electroencephalogram and local cerebral glucose utilization. Brain Res 585:177-183.

Bubser M, Keseberg U, Notz PK, Schmidt WJ (1992) Differential behavioural and neurochemical effects of competitive and non-competitive NMDA receptor antagonists in rats. Eur $\mathrm{J}$ Pharmacol 229:75-82.

Buchan A, Pulsinelli WA (1990) Hypothermia but not the N-methyl-Daspartate antagonist, MK-801, attenuates neuronal damage in gerbils subjected to transient global ischemia. J Neurosci 10:311316.

Buchan A, Li H, Pulsinelli WA (1991) The $N$-methyl-D-aspartate antagonist, MK-801, fails to protect against neuronal damage caused by transient, severe forebrain ischemia in adult rats. $J$ Neurosci 11:1049-1056.

Buchan AM, Slivka A, Xue D (1992) The effect of the NMDA receptor antagonist MK-801 on cerebral blood flow and infarct volume in experimental focal stroke. Brain Res 574:171-177.

Candelise L, Landi G, Orazio EN, Boccardi E (1985) Prognostic significance of hyperglycemia in acute stroke. Arch Neurol 42:661663.

Capes SE, Hunt D, Malmberg K, Pathak P, Gerstein HC (2001) Stress hyperglycemia and prognosis of stroke in nondiabetic and diabetic patients: a systematic overview. Stroke 32:2426-2432.

Chen J, Hu R, Liao H, Zhang Y, Lei R, Zhang Z, Zhuang Y, Wan Y, Jin $\mathrm{P}$, Feng $\mathrm{H}$, Wan $\mathrm{Q}$ (2017) A non-ionotropic activity of NMDA receptors contributes to glycine-induced neuroprotection in cerebral ischemia-reperfusion injury. Sci Rep 7:3575.

Corbett D, Evans S, Thomas C, Wang D, Jonas RA (1990) MK-801 reduced cerebral ischemic injury by inducing hypothermia. Brain Res 514:300-304.

de Courten-Myers G, Myers RE, Schoolfield L (1988) Hyperglycemia enlarges infarct size in cerebrovascular occlusion in cats. Stroke 19:623-630.

de Courten-Myers GM, Kleinholz M, Wagner KR, Myers RE (1994) Normoglycemia (not hypoglycemia) optimizes outcome from middle cerebral artery occlusion. J Cereb Blood Flow Metab 14:227236.

Dietrich WD, Alonso O, Busto R (1993) Moderate hyperglycemia worsens acute blood-brain barrier injury after forebrain ischemia in rats. Stroke 24:111-116.

Esposito E, Li W, T Mandeville E, Park JH, Şencan I, Guo S, Shi J, Lan J, Lee J, Hayakawa K, Sakadzõić S, Ji X, Lo EH (2020) Potential circadian effects on translational failure for neuroprotection. Nature 582:395-398.

Gerriets T, Stolz E, Walberer M, Kaps M, Bachmann G, Fisher M (2003) Neuroprotective effects of MK-801 in different rat stroke models for permanent middle cerebral artery occlusion: adverse effects of hypothalamic damage and strategies for its avoidance. Stroke 34:2234-2239. 
Gill R, Brazell C, Woodruff GN, Kemp JA (1991) The neuroprotective action of dizocilpine (MK-801) in the rat middle cerebral artery occlusion model of focal ischaemia. Br J Pharmacol 103:2030-2036.

Ginsberg MD, Welsh FA, Budd WW (1980) Deleterious effect of glucose pretreatment on recovery from diffuse cerebral ischemia in the cat. I. Local cerebral blood flow and glucose utilization. Stroke 11:347-354.

Gray CS, Hildreth AJ, Sandercock PA, O'Connell JE, Johnston DE, Cartlidge NE, Bamford JM, James OF, Alberti KG; GIST Trialists Collaboration (2007) Glucose-potassium-insulin infusions in the management of post-stroke hyperglycaemia: the UK Glucose Insulin in Stroke Trial (GIST-UK). Lancet Neurol 6:397-406.

Hatfield RH, Gill R, Brazell C (1992) The dose-response relationship and therapeutic window for dizocilpine (MK-801) in a rat focal ischaemia model. Eur J Pharmacol 216:1-7.

Hill MD, Goyal M, Menon BK, Nogueira RG, McTaggart RA, Demchuk AM, Poppe AY, Buck BH, Field TS, Dowlatshahi D, van Adel BA, Swartz RH, Shah RA, Sauvageau E, Zerna C, Ospel JM, Joshi M, Almekhlafi MA, Ryckborst KJ, Lowerison MW, et al. (2020) Efficacy and safety of nerinetide for the treatment of acute ischaemic stroke (ESCAPE-NA1): a multicentre, double-blind, randomised controlled trial. Lancet 395:878887.

Hu R, Chen J, Lujan B, Lei R, Zhang M, Wang Z, Liao M, Li Z, Wan Y, Liu F, Feng H, Wan Q (2016) Glycine triggers a non-ionotropic activity of GluN2A-containing NMDA receptors to confer neuroprotection. Sci Rep 6:34459.

Ikonomidou C, Mosinger JL, Olney JW (1989) Hypothermia enhances protective effect of MK-801 against hypoxic/ischemic brain damage in infant rats. Brain Res 487:184-187.

Johnston KC, Bruno A, Pauls Q, Hall CE, Barrett KM, Barsan W, Fansler A, Van de Bruinhorst K, Janis S, Durkalski-Mauldin VL; Neurological Emergencies Treatment Trials Network and the SHINE Trial Investigators (2019) Intensive vs standard treatment of hyperglycemia and functional outcome in patients with acute ischemic stroke: the SHINE randomized clinical trial. JAMA 322:326-335.

Kessels HW, Nabavi S, Malinow R (2013) Metabotropic NMDA receptor function is required for $\beta$-amyloid-induced synaptic depression. Proc Natl Acad Sci USA 110:4033-4038.

Lai TW, Zhang S, Wang YT (2014) Excitotoxicity and stroke: identifying novel targets for neuroprotection. Prog Neurobiol 115:157188.

LeBlanc MH, Vig V, Smith B, Parker CC, Evans OB, Smith EE (1991) MK-801 does not protect against hypoxic-ischemic brain injury in piglets. Stroke 22:1270-1275.

Liu CW, Liao KH, Tseng H, Wu CM, Chen HY, Lai TW (2020) Hypothermia but not NMDA receptor antagonism protects against stroke induced by distal middle cerebral arterial occlusion in mice. PLoS One 15:e0229499.

Liu CW, Liao KH, Wu CM, Chen HY, Wang EY, Lai TW (2021) Stroke injury induced by distal middle cerebral artery occlusion is resistant to $\mathrm{N}$-methyl-d-aspartate receptor antagonism in FVB/NJ mice. Neuroreport 32:1122-1127.

Liu YC, Lee YD, Wang HL, Liao KH, Chen KB, Poon KS, Pan YL, Lai TW (2017) Anesthesia-induced hypothermia attenuates earlyphase blood-brain barrier disruption but not infarct volume following cerebral ischemia. PLoS One 12:e0170682.

Lo EH, Matsumoto K, Pierce AR, Garrido L, Luttinger D (1994) Pharmacologic reversal of acute changes in diffusion-weighted magnetic resonance imaging in focal cerebral ischemia. $\mathrm{J}$ Cereb Blood Flow Metab 14:597-603.

Ma J, Endres M, Moskowitz MA (1998) Synergistic effects of caspase inhibitors and MK-801 in brain injury after transient focal cerebral ischaemia in mice. Br J Pharmacol 124:756-762.

Margaill I, Parmentier S, Callebert J, Allix M, Boulu RG, Plotkine M (1996) Short therapeutic window for MK-801 in transient focal cerebral ischemia in normotensive rats. J Cereb Blood Flow Metab 16:107-113.
McDonald JW, Silverstein FS, Johnston MV (1987) MK-801 protects the neonatal brain from hypoxic-ischemic damage. Eur $\mathrm{J}$ Pharmacol 140:359-361.

Memezawa H, Zhao Q, Smith ML, Siesjö BK (1995) Hyperthermia nullifies the ameliorating effect of dizocilpine maleate (MK-801) in focal cerebral ischemia. Brain Res 670:48-52.

Myers RE, Yamaguchi S (1977) Nervous system effects of cardiac arrest in monkeys. Preservation of vision. Arch Neurol 34:6574.

Nabavi S, Kessels HW, Alfonso S, Aow J, Fox R, Malinow R (2013) Metabotropic NMDA receptor function is required for NMDA receptor-dependent long-term depression. Proc Natl Acad Sci USA 110:4027-4032.

Nellgård B, Wieloch T (1992) Postischemic blockade of AMPA but not NMDA receptors mitigates neuronal damage in the rat brain following transient severe cerebral ischemia. J Cereb Blood Flow Metab 12:2-11.

Nellgård B, Gustafson I, Wieloch T (1991) Lack of protection by the $\mathrm{N}$-methyl-D-aspartate receptor blocker dizocilpine (MK-801) after transient severe cerebral ischemia in the rat. Anesthesiology 75:279-287.

Olney JW, Ikonomidou C, Mosinger JL, Frierdich G (1989) MK-801 prevents hypobaric-ischemic neuronal degeneration in infant rat brain. J Neurosci 9:1701-1704.

Ozyurt E, Graham DI, Woodruff GN, McCulloch J (1988) Protective effect of the glutamate antagonist, MK-801 in focal cerebral ischemia in the cat. J Cereb Blood Flow Metab 8:138143.

Park CK, Nehls DG, Graham DI, Teasdale GM, McCulloch J (1988a) The glutamate antagonist MK- 801 reduces focal ischemic brain damage in the rat. Ann Neurol 24:543-551.

Park CK, Nehls DG, Graham DI, Teasdale GM, McCulloch J (1988b) Focal cerebral ischaemia in the cat: treatment with the glutamate antagonist MK-801 after induction of ischaemia. J Cereb Blood Flow Metab 8:757-762.

Pulsinelli WA, Waldman S, Rawlinson D, Plum F (1982) Moderate hyperglycemia augments ischemic brain damage: a neuropathologic study in the rat. Neurology 32:1239-1246.

Pulsinelli WA, Levy DE, Sigsbee B, Scherer P, Plum F (1983) Increased damage after ischemic stroke in patients with hyperglycemia with or without established diabetes mellitus. Am J Med 74:540-544.

Riddle MC, Hart J (1982) Hyperglycemia, recognized and unrecognized, as a risk factor for stroke and transient ischemic attacks. Stroke 13:356-359.

Rod MR, Auer RN (1989) Pre- and post-ischemic administration of dizocilpine (MK-801) reduces cerebral necrosis in the rat. Can J Neurol Sci 16:340-344.

Rod MR, Whishaw IQ, Auer RN (1990) The relationship of structural ischemic brain damage to neurobehavioural deficit: the effect of postischemic MK-801. Can J Psychol 44:196-209.

Scott JF, Robinson GM, French JM, O’Connell JE, Alberti KG, Gray CS (1999) Prevalence of admission hyperglycaemia across clinical subtypes of acute stroke. Lancet 353:376-377.

Siemkowicz E (1981) Hyperglycemia in the reperfusion period hampers recovery from cerebral ischemia. Acta Neurol Scand 64:207216.

Siemkowicz E, Hansen AJ (1978) Clinical restitution following cerebral ischemia in hypo-, normo- and hyperglycemic rats. Acta Neurol Scand 58:1-8.

Swan JH, Meldrum BS (1990) Protection by NMDA antagonists against selective cell loss following transient ischaemia. J Cereb Blood Flow Metab 10:343-351.

Tonkiss J, Rawlins JN (1991) The competitive NMDA antagonist AP5, but not the non-competitive antagonist MK801, induces a delay-related impairment in spatial working memory in rats. Exp Brain Res 85:349-358.

Warner MA, Neill KH, Nadler JV, Crain BJ (1991) Regionally selective effects of NMDA receptor antagonists against ischemic 
brain damage in the gerbil. J Cereb Blood Flow Metab 11:600610.

Weilinger NL, Lohman AW, Rakai BD, Ma EM, Bialecki J, Maslieieva V, Rilea T, Bandet MV, Ikuta NT, Scott L, Colicos MA, Teskey GC, Winship IR, Thompson RJ (2016) Metabotropic NMDA receptor signaling couples Src family kinases to pannexin-1 during excitotoxicity. Nat Neurosci 19:432-442.

Weir CJ, Murray GD, Dyker AG, Lees KR (1997) Is hyperglycaemia an independent predictor of poor outcome after acute stroke? Results of a long-term follow up study. BMJ 314:1303-1306.

Welsh FA, Ginsberg MD, Rieder W, Budd WW (1980) Deleterious effect of glucose pretreatment on recovery from diffuse cerebral ischemia in the cat. II. Regional metabolite levels. Stroke 11:355363.

Willetts J, Balster RL, Leander JD (1990) The behavioral pharmacology of NMDA receptor antagonists. Trends Pharmacol Sci 11:423-428.

Williams LS, Rotich J, Qi R, Fineberg N, Espay A, Bruno A, Fineberg SE, Tierney WR (2002) Effects of admission hyperglycemia on mortality and costs in acute ischemic stroke. Neurology 59:67-71.

Yip PK, He YY, Hsu CY, Garg N, Marangos P, Hogan EL (1991) Effect of plasma glucose on infarct size in focal cerebral ischemiareperfusion. Neurology 41:899-905. 